“C 2018 IEEE. Personal use of this material is permitted. Permission from IEEE must be obtained for all other uses, in any current or future media, including reprinting/republishing this material for advertising or promotional purposes, creating new collective works, for resale or redistribution to servers or lists, or reuse of any copyrighted component of this work in other works." 


\section{Skew Angle Optimization Analysis of a Permanent Magnet Synchronous Motor for EVs}

\author{
Xiaodong Sun, Zhou Shi, Long Chen, Zebin Yang, \\ Automotive Engineering Research Institute \\ Jiangsu University \\ Zhenjiang, China (212013) \\ xdsun@ujs.edu.cn, shizhoujiangda@163.com, \\ chenlong@ujs.edu.cn, zbyang@ujs.edu.cn,
}

\begin{abstract}
In this paper, the skew angle of the permanent magnet synchronous motor (PMSM) for electric vehicles (EVs) is studied. The stability of the output torque of the driving motor is important for the EVs. The influence of skew angle on the Backelectromotive force, cogging torque, and output torque are studied by finite element analysis. The optimum skew angle of the stator slot is analyzed for the prototype. The results show that the proposed PMSM has better comprehensive performance after the optimization of the skew angle.
\end{abstract}

Keywords-component; electric vehicles; permanent magnet synchronous motor; skew angle; torque ripple

\section{INTRODUCTION}

In recent years, with the rapid development of electric vehicles (EVs), a lot of research is devoted to the research of driving motors [1-5]. Especially the research of permanent magnet synchronous motor (PMSM) has become one of the hottest spots in the EVs studies due to its higher power density, higher efficiency, easier cooling, and higher reliability. In particular, the performance of PMSMs at low speed is far better than other drive motors such as induction motors and switch reluctance motors. However, the torque ripple of permanent magnet motor at low speed is still urgent to be solved. The main solutions to reduce the torque ripple are suitable permanent magnet structure design, well matching of pole and slot numbers, and skew-slot.

A great deal of studies are devoted to the research of suitable permanent magnet torque structure design to reduce the torque ripple [6-8]. There are also some researches focused on the skew-slot while existing research mainly focuses on the positive rotation performance. However, if the skew angle is not an integer multiple of slot pitch the skew-slot will have different influence on the positive rotation performance and negative rotation performance. As stability in the state of reversing is important for EVs and there is no idle wheel structure in most EVs. So when skew-slot design is adopt in a PMSM, the effects of skew angle on the positive rotation performance and negative rotation performance should be studied respectively.

The purpose of this paper is to analysis the skew angle for the PMSM for an EV. Firstly, the relationship between the torque ripple and the skew angle is investigated in details. Then a 24/8-pole PMSM is adopted for the study. The positive rotation performance and negative rotation performance of the

\author{
Gang Lei, Jian Guo Zhu, You Guang Guo \\ School of Electrical, Mechanical and Mechatronic Systems \\ University of Technology, Sydney \\ Sydney, Australia (2007) \\ Gang.Lei@uts.edu.au,jianguo.zhu@uts.edu.au, \\ Youguang.Guo-1@uts.edu.au
}

PMSM under different skew angle is studied by finite element analysis (FEA).

\section{PERFORMANCE ANALYSIS}

A 24/8-pole PMSM is adopted for the study which structure is shown in Fig.1. Here $\alpha$ is used to represent for the skew angle which is measured in mechanical angle. The performance analysis of the PMSM mainly includes the analysis of the winding back electromotive force (EMF), the flux linkage, the cogging torque, and the output torque. The FEM is employed to analyze the system performance. Integer skew slot was adopted in most previous studies, which can effectively reduce the cogging torque but reduce the output torque at the same time. In this paper decimal skew slot will be studied to find a best skew angle for the proposed PMSM.

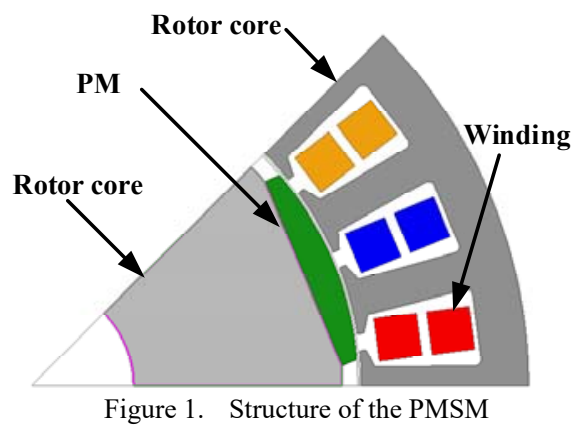

\section{A. Back EMF}

Fig. 2 presents no-load back EMF waveforms of the PMSM under different skew angle. As shown, the amplitude of the back EMF waveforms reduces with the increase of $\alpha$.

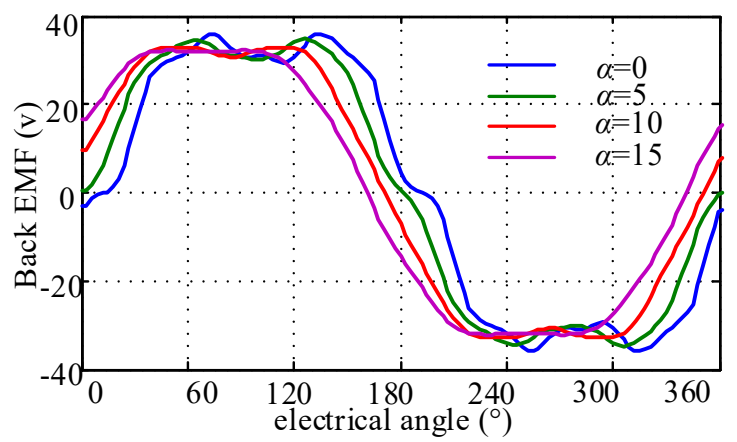

Figure 2. Back EMF waveforms @2500r/min 


\section{B. Cogging Torque}

Cogging Torque is the most important part of the no-load performance which is shown in Fig. 3. As shown, when the $\alpha$ increase, the cogging torque reduced obviously.

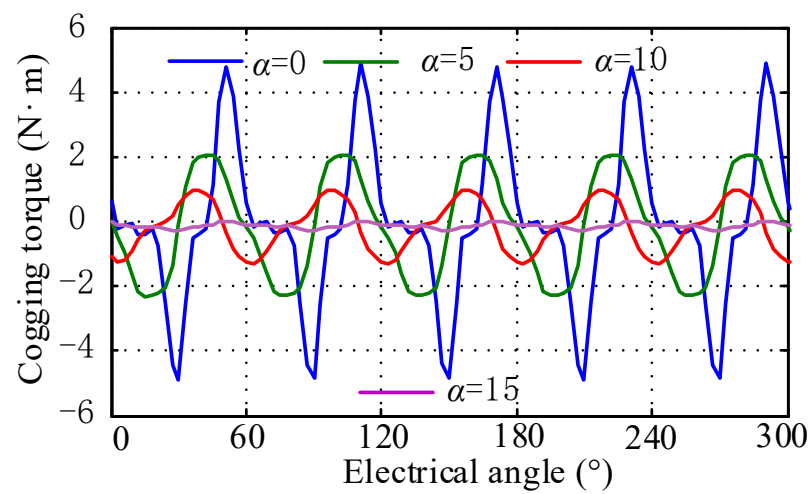

Figure 3. Cogging torque

\section{Output Torque}

As the main purpose is to reduce the torque ripple, the output torque is the most important point which need to be analyzed. The output torque under different skew angle is shown in Fig. 4. As shown, the torque ripple reduces with the increase of $\alpha$. However, the average torque will reduce with the increase of $\alpha$.

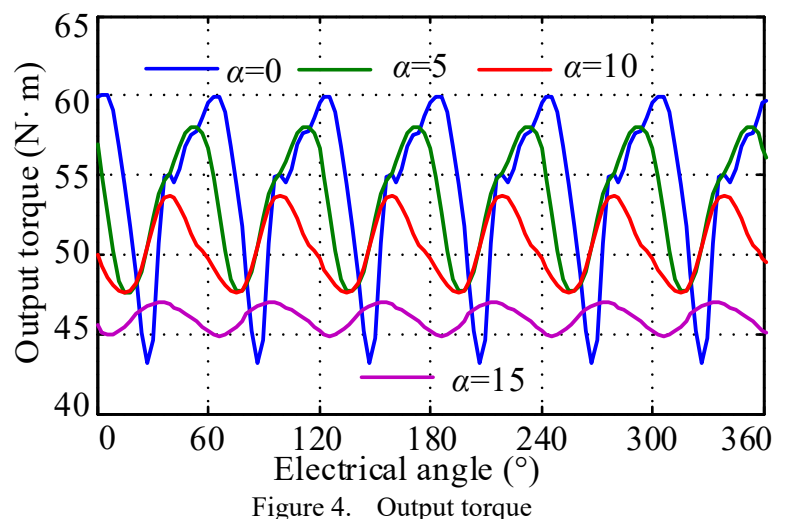

Besides the influences of the skew slot on the positive rotation and negative rotation are also different which will be discussed in detail in the full paper.

\section{ANALYSIS OF THE OPTIMUM SKEW ANGLE}

In section II, the influence of skew slot on the Back EMF, cogging torque, and output torque has been studied. The skew slot can reduce the torque ripple, but cause the decline of average torque at same time. Besides, the influences of the skew slot on the positive rotation and negative rotation are different. So it is essential to find a suitable skew angle.

The average torque and torque ripple of motor at different skew angle both positive rotation and negative rotation of are taken into consideration. Thus a multi-objective optimization problem can be formulated as

$$
\begin{aligned}
& \max :\left\{F(\alpha)=T_{\text {Pave }} \cdot T_{\text {Nave }} \cdot\left(P_{\mathrm{TP}} \% \cdot P_{T \mathrm{~N}} \%\right)^{-1.5} \cdot T_{\mathrm{cog}}{ }^{-1}\right\} \\
& \text { s.t. }\{\alpha \in(0,15)\}
\end{aligned}
$$

where $T_{\text {Pave }}$ and $T_{\text {Nave }}$ are the positive rotation and negative rotation average output torque of the PMSM, $P_{\mathrm{TP}} \%$ and $P_{\mathrm{TN}} \%$ are the torque ripple, and $T_{\operatorname{cog}}$ is the amplitude of the PMSM. Finally when $\alpha=12$ comprehensive performance of the proposed PMSM is the best.

\section{CONCLUSIONS}

This paper has investigated the influence of skew angle on the performance of the PMSMs. The results show that the skew slot do reduce the torque ripple and cogging torque while decline the output torque at same time. An objective optimization function is put forward and the optimum skew angle of the proposed PMSM is obtained through the optimization function.

\section{ACKNOWLEDGEMENT}

This work was supported by the National Natural Science Foundation of China under Projects 51305170, 51475214, and 51475213, the Natural Science Foundation of Jiangsu Province of China under Projects BK20170071, the Key Project of Natural Science Foundation of Jiangsu Higher Education Institutions under Project 17KJA460005, the Six Categories Talent Peak of Jiangsu Province under Projects 2015-XNYQC003 and 2014-ZBZZ-017, the "333 project" of Jiangsu Province under Project BRA2017441, and the Priority Academic Program Development of Jiangsu Higher Education Institutions (PAPD).

\section{REFERENCES}

[1] I. Petrov, M. Niemela, P. Ponomarev, and J. Pyrhonen, "Rotor surface ferrite permanent magnets in electrical machines: advantages and limitations," IEEE Transactions on Industrial Electronics, vol. 64, pp. 5314-5322, July. 2017.

[2] X. Sun, L. Chen, Z. Yang, and H. Zhu. "Speed-sensorless vector control of a bearingless induction motor with artificial neural network inverse speed observer," IEEE/ASME Transactions on Mechatronics, 3, vol. 18. No 4, pp 1357-1366, Aug. 2013.

[3] G. Lei, J. Zhu, and Y. Guo, "Multidisciplinary Design Optimisation Methods for Electrical Machines and Drive Systems," Springer-Verlag. Berlin Heidelberg, 2016 pp 25-69.

[4] X. Sun, C. Long, Z. Yang. "Overview of bearingless permanent magnet synchronous motors," IEEE Transactions on Industrial Electronics, vol. 60, pp. 5528-5538, Dec. 2013.

[5] B. S. Gagas, K. Sasaki, T. Fukushige, A. Athavale, T. Kato, and R. D. Lorenz, "Analysis of Magnetizing Trajectories for Variable Flux PM Synchronous Machines Considering Voltage, High-Speed Capability, Torque Ripple, and Time Duration," IEEE Transactions on Industry Applications, vol. 52, pp. 4029-4038, Oct. 2016.

[6] R. P. Deodhar, A. Pride and J. J. Bremner, "Design method and experimental verification of a novel technique for torque ripple reduction in stator claw-pole PM machines," IEEE Transactions on Industry Applications, vol. 51, pp. 3743-3750, Oct 201

[7] X. Sun, Z. Shi, L. Chen, and Z. Yang. "Internal model control for a bearingless permanent magnet synchronous motor based on inverse system method," IEEE Transactions on Energy Conversion, vol. 31. pp. 1539-1548, Nov. 2016.

[8] G. Lei, J. Zhu, Y. Guo, C. Liu and B. Ma, "A review of design optimization methods for electrical machines", Energies, vol. 10, no. 12, Art. no. 1962, pp. 1-31, Nov. 2017. 